\title{
EXPLORATION OF THE USE OF SENSORY DIETS IN OCCUPATIONAL THERAPY
}

Allison Hunt, OTS, Morganne Peterson, OTS, Emily White, OTS, Julia Wilbarger, PhD, OTR/L (Faculty Advisor)

Occupational Therapy Department, Dominican University of California

\section{BACKGROUND}

- Termed by Patricia Wilbarger, the "sensory diet" is used as an intervention to provide sensory based strategies throughout an individual's day to facilitate an optimal level of arousal in a state of calm alertness to promote occupational performance (Wan Yunus, Liu, Bissett, \& Penkala, 2015).

- Using a nutritional diet as a metaphor, Wilbarger explained that just as healthy meals need an array of different food choices to be nutritionally balanced, the correct combination of sensory input is necessary to have optimal occupational performance (Wilbarger P., 1995).

- A sensory diet is an extension of therapeutic OT intervention that can be used in everyday life (Bundy, Lane, \& Murray, 2002).

\section{PURPOSE}

- To fill the gap in literature and to further examine the use of sensory diets in the filed of occupational therapy through an online survey completed by OTAC members.

\section{METHODOLOGY}

- Participants: OTAC members

- 98 survey responses acquired via SurveyMonkey

- Survey consisted of multiple choice, fill in the blank, and check all that apply questions

- Data was interpreted through Excel and SPSS

\section{RESULTS}

\section{Percentage of Clinical Populations Using} Sensory Diets

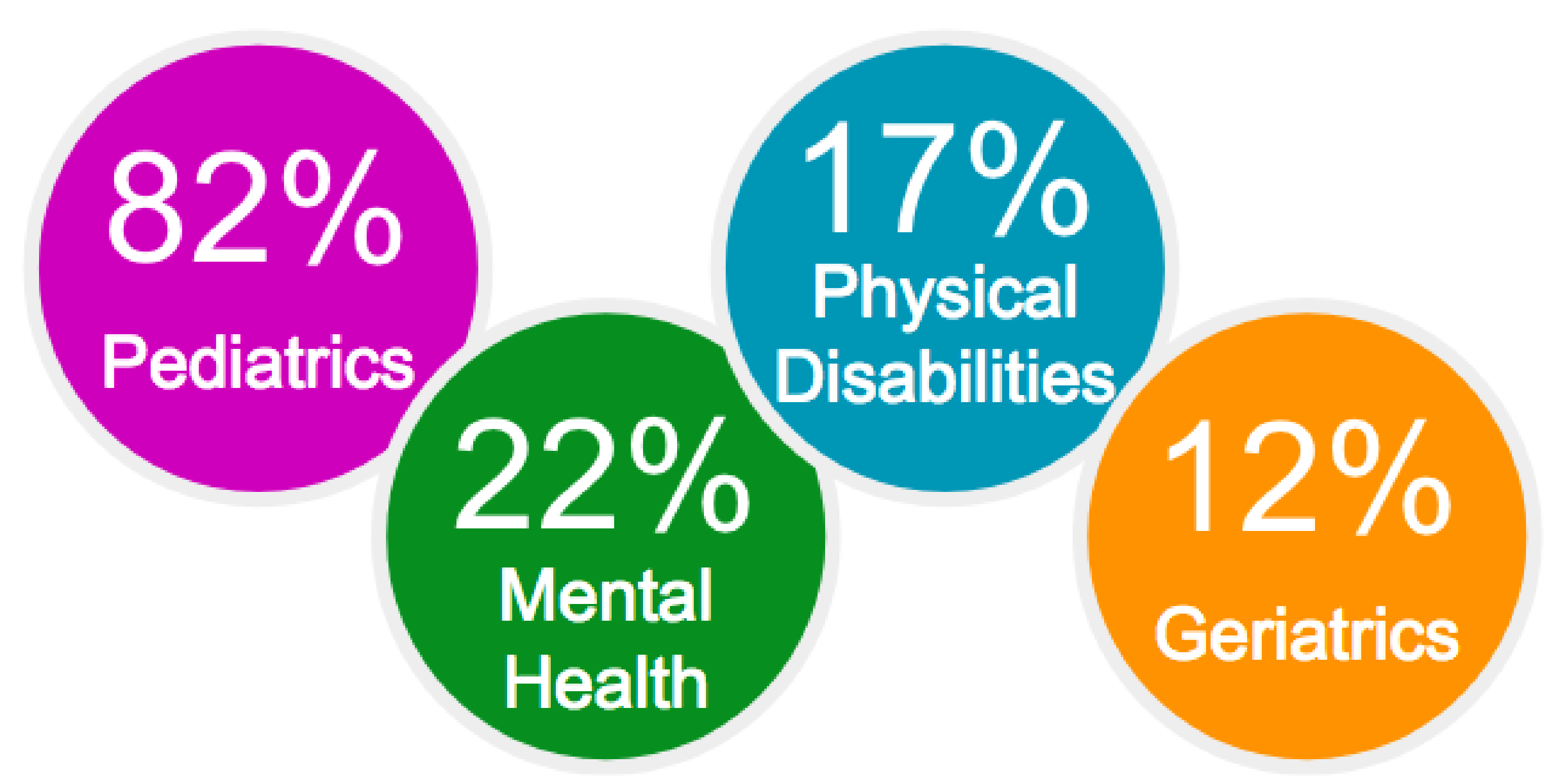

Other Terms Used By Practitioners<smiles>[14CH3][14CH2][GeH3]</smiles>

Sensory Stimulation Sensory Strategy Sensory Diet

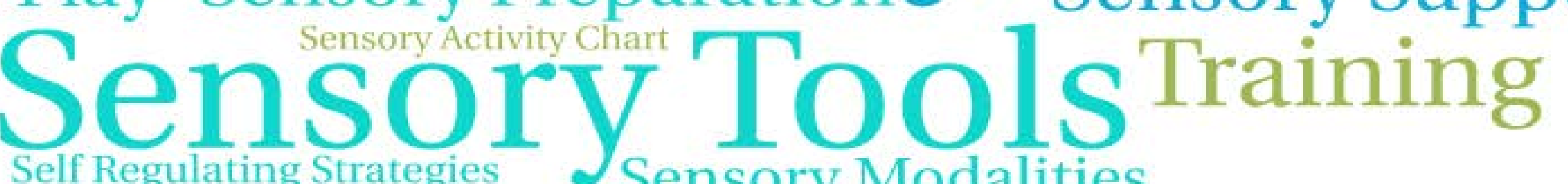
Home Program

Reported Modalities Used Across Populations

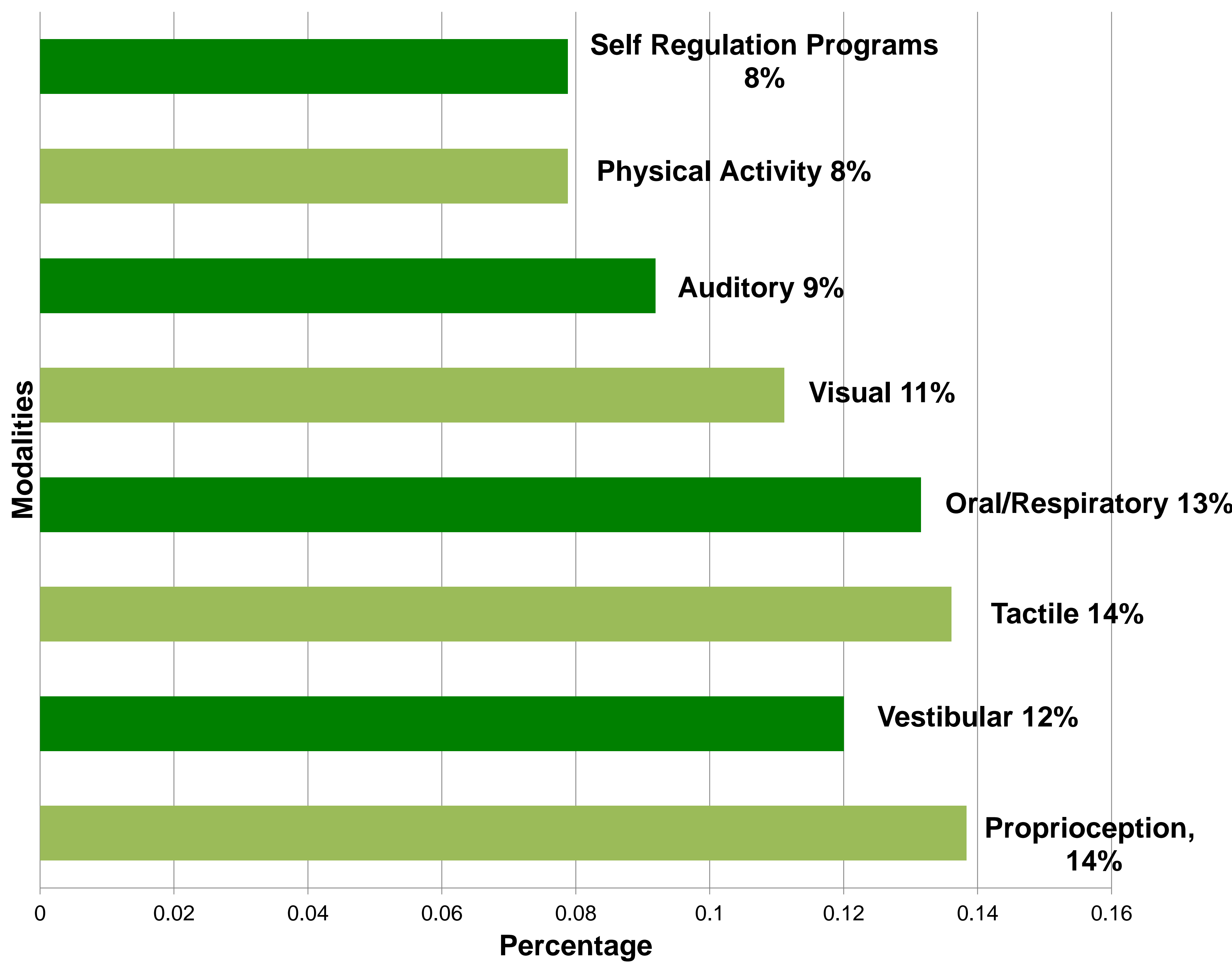

\section{CONCLUSIONS}

- There is an overall misunderstanding associated with term sensory diet among OT practitioners, clients, and caregivers.

- Sensory diets can be used as an intervention for clients across the lifespan to promote optimal performance.

- Sensory diets include a multisensory approach regardless of the population.

\section{IMPLICATIONS FOR PRACTICE}

- Sensory diets are applicable to many populations in various clinical settings.

- An alternative name that is more easily understandable and used universally would help decrease confusion among clinicians.

- Continuing education classes may be helpful for clinicians to increase their understanding of sensory diets to promote better outcomes.

- Further research is needed to better understand the effectiveness of sensory diets and how they are implemented.

\section{AKNOWLEDGEMENTS \& REFERENCES}

We would like to acknowledge and thank the OTAC members who participated in our study as well as Allison Bordessa for her assistance in creating our study.

Bundy, A., Lane, S., \& Murray, E. (2002). Sensory integration: Theory and practice. Philadelphia, Pennsylvania: F.A. Davis Company

5). Sensory-Based

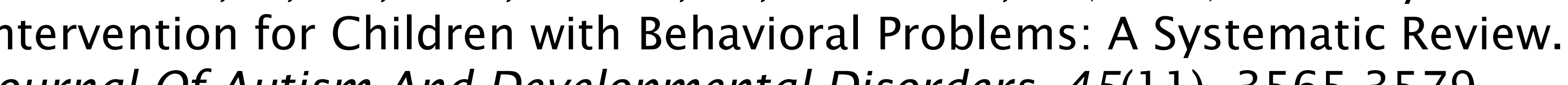
Wilbarger, P. (1995). The Sensory Diet: Activity Programs Based on Sensory Processing Theory. American Occupational Therapy Association, 18(2), 1-3. 